\title{
Dynamics of body composition in male patients during chronic obstructive pulmonary disease (COPD) development
}

The authors declare no financial disclosure

\begin{abstract}
Introduction: The various distribution of fat mass (FM) and lean mass (LM) during COPD development is not yet researched. Material and methods: 82 male patients (40-67 years) with acute exacerbation of COPD and 19 comparable healthy males (the control group) were examined by dual-energy X-ray absorptiometry. The patients were divided into 3 groups according to COPD severity: $1^{\text {st }}-19$ (GOLD I stage); $2^{\text {nd }}-43$ (GOLD II) and $3^{\text {rd }}-20$ (GOLD III).

Results: The patients of $3^{\text {rd }}$ group had lower indices of FM, LM, bone mineral component (BMC) vs. the control and $1^{\text {st }}, 2^{\text {nd }}$ groups. A significant increase in FM share was noted in android and gynoid regions, trunk, legs and arms in $2^{\text {nd }}$ groups vs. the control with the decline of these parameters in the $3^{\text {rd }}$ group below the control level. A greater proportion of FM in $1^{\text {st }}$ and $2^{\text {nd }}$ groups was distributed in android and trunk regions vs. the control. TNF- $\alpha$ and leptin levels were significantly increased by $12 \%, 15 \% 17 \%$ and by $18 \%, 75 \%, 79 \%$ respectively in $1^{\text {st }}, 2^{\text {nd }}, 3^{\text {rd }}$ groups vs. the control, while free testosterone level was lower in these groups vs. the control (by $28 \%, 30 \%$ and $47 \%$ respectively; $p<0,05$ ).

Conclusions: Body mass index (BMI) was within the control range in mild-moderate COPD patients in spite of LM, FM and BMC changes. The level of LM and BMC was decreased during COPD progression, while FM was increased in mild-moderate COPD and then it was decreased in severe COPD.
\end{abstract}

Key words: COPD, body composition, lean mass, fat mass, leptin

Pneumonol Alergol Pol 2015; 83: 424-430

\section{Introduction}

The picture of systemic manifestations of COPD is not complete without the evaluation of patient's body composition (BC) parameters [1]. Repeated COPD exacerbations are accompanied by an impaired energy balance that has a negative consequence on patient's BC [2]. In turn, BC abnormalities may be a significant contributor to the low-grade systemic inflammation and may indirectly stimulate stimulate COPD progression. Thus, BMI loss (from $10 \%$ in mild to $50 \%$ in severe COPD) has an unfavorable impact on disease development due to decreased skeletal and respiratory muscle strength (with subsequent lower exercise capacity), resistance to infection as well as the higher frequencies of exacerbations [3-5]. The reasons for progressive loss of tissue mass and BMI include [6, 7]: increased load on the respiratory muscles (enhanced by $15 \%$ breathing work and its energy costs at rest and during exercise), a high level of proinflammatory cytokines and basic metabolism (increased by $25 \%$ vs. the healthy persons), to a smaller degree - expressed hypoxia and tissue oxygen debt, oxidative stress, the use of long acting $\beta_{2}$-agonists and teophylline, smoking,hypoandrogenism, impaired regulation of hormones that reduces food intake, disorders of gastro-intestinal tract and protein metabolism (with increased protein degeneration). 
BMI does not give the complete information about BC changes in COPD patients. Thus, loss of LM is not always accompanied by a loss of BMI and may occur in the case of normal patient's BMI level against the background of FM component excess [8]. Only $17 \%$ of the patients with chronic respiratory failure had a BMI $<20 \mathrm{~kg} / \mathrm{m}^{2}$ as well as only $5 \%$ of mild COPD patients had a BMI $<18.5$ $\mathrm{kg} / \mathrm{m}^{2}$ vs. $30 \%$ of patients with severe COPD [9, 10]. Three malnutrition profiles can be identified in advanced COPD [11]: underweight patients with concomitant depletion of body LM (60\%) or with a normal LM (20\%) and the patients of normal body weight with depletion of LM. A shift in BC structure towards a relative abundance of FM and reduced LM during COPD exacerbation (due to increased: hypoxemia, sympathetic tone, using $\beta_{2}$-agonists and systemic corticoids - sCS) was revealed. LM loss (significant problem in $1 / 3$ of moderate to severe COPD patients) may adversely affect the peripheral skeletal and respiratory muscles (development of their weakness) and respiratory function $[5,12]$.

The metabolic syndrome is observed in up to $53 \%$ of COPD patients in GOLD grade 2 [13] and it was associated with higher levels of the systemic inflammation markers and frequency of exacerbations [14]. Overweight and obesity were often observed (in $1 / 3$ and $1 / 5$ of cases respectively) in COPD patients [15] and they did not worsen the respiratory function and symptoms in many cases of mild-to-moderate COPD as well as they had even a protective effect in relation to mortality [10]. But severe obesity favors the disorders of carbohydrate metabolism, pulmonary dysfunction (reduced compliance of the chest wall, lung volume and impaired airway function) and appearance of cardiovascular pathology $[14,16]$.

Hormonal changes are also closely linked to disturbed BC. Gradually decreasing levels of circulated androgens in males with age is related to increased levels of total and abdominal body FM [17]. A key role in the relationship between lung pathology and adipose tissue play adipokines (APN) - leptin and adiponektin, for which important source is an abdominal subcutaneous and visceral FM. APN significantly influence the inflammatory process, immune response, lipid metabolism and regulation of energy balance [18]. Pro-inflammatory effects of APN may dominate under the certain conditions. Thus, visceral obesity and visceral FM in overweight COPD patients may be associated with a high level of proinflammatory cytokines (TNF- $\alpha$ ) and leptin as well as have a greater inflammatory ef- fect $[19,20]$. It was shown, that sCS and TNF- $\alpha$ induce increased leptin level in normal subjects, besides TNF- $\alpha$ may decrease all the components of BC. The increased levels of TNF- $\alpha$ and leptin in blood circulation favor decreased appetite and food intake in COPD patients, mostly with severe hypoxia, which induces increased leptin expression and intensified fat metabolism in COPD [12, 19]. Leptin resistance is common in overweight COPD patients and results in lung hypoventilation [21]. Systemic leptin concentration may be disproportionately higher in COPD, reflecting a greater airway inflammation and disease severity [22].

The purpose of this study was to evaluate distribution of $\mathrm{BC}$ as well as the relationship between the latter and TNF- $\alpha$, leptin and free testosterone levels in relation to COPD development.

\section{Material and methods}

The study was undertaken at the Pulmonology Department of the $10^{\text {th }}$ Minsk Clinical Hospital in the years 2009-2013. All participants gave their written informed consent. The study protocol was approved by the Human Studies Committee on Research Ethics at the Belarusian State Medical University. The inclusion criteria for the study were the following: males aged 40-69 years with different COPD grades and $\mathrm{FEV}_{1}$ increase $<15 \%$ in bronchodilator test. Exclusion criteria included substantial uncontrolled co-morbidities that may affect nutritional status (uncontrolled heart failure and diabetes, chronic renal failure, neoplasms). The study group consisted of 82 COPD male patients with acute exacerbation who were divided into three groups according to the severity of disease (mild $-\mathrm{COPD}_{1}$, moderate $-\mathrm{COPD}_{2}$ and severe - $\mathrm{COPD}_{3}$ ) using post-bronchodilator $\mathrm{FEV}_{1}$ and clinical symptoms. The diagnosis of COPD and its severity was based on the GOLD guidelines published in 2011. The intensity of dyspnea was defined according to a modified MRC questionnaire. The clinical investigation of these patients on admission included: self-reported co-morbidities, smoking status and previous treatment, spirometry (using a portable spirometer "Spirovit SP-10" of "Shiller"), physical examination, day-time pulseoximetry, chest radiography and blood laboratory analyses. The patients $\left(m_{0}\right.$ stly $\mathrm{COPD}_{2-3}$ ) were treated with a combination of inhaled long-acting anticholinergic (or $\beta_{2}$-agonists) plus inhaled and sometimes sCS ( 5 days of dexametasone intravenously, $4 \mathrm{mg}$ a day) as well as broad spectrum antibiotics if there was clinical evidence of Type 1 or 2 exacerbation according 
to Anthonisen criteria. The control group consisted of 19 healthy male persons of comparable age, smoking status, BMI and without history of chronic diseases.

TNF- $\alpha$, leptin and free testosterone levels were detected by immynoenzyme (ELISA) methods. Distribution of BC parameters was measured using dual-energy X-ray absorptiometry (DXA) ("Prodigy Lunar", General Electric Medical Systems, USA). We calculated: FM index (FMI = $\mathrm{FM} /$ height $\left.^{2}\right)$, LM index $\left(\mathrm{LMI}=\mathrm{LM} /\right.$ height $\left.^{2}\right)$ that reflects non-fat and non-bone soft tissue content, skeletal muscle index (SMI $=$ fat-free mass of arms + legs $/$ height $^{2}$ ) and bone mineral component index (BMCI $=$ bone mineral component of body/height ${ }^{2}$ ).

The statistical analysis was performed using Statistica 8.0 software (2007, Statsoft Inc., USA). The preliminary analysis of the variables under consideration was a Shapiro-Wilk test of correspondence to normal distribution. The results of the analysis were shown as median and interquartile range (25-75\%) because all the parameters differed from normal distribution. The comparison of non-parametric parameters in two independent groups was carried out using a Mann-Whitney test, while in three or more independent groups it was performed using the Kruskal-Wallis rank sum test. Fisher's exact test was used to detect statistically significant differences between independent groups according to the frequency characteristic of the investigated parameter. Spearman's rank correlation coefficient (rs) was used to describe the relationship between the two quantitative variables that differed from normal distribution. The level of statistical significance was set at $\mathrm{p}<0.05$.

\section{Results}

As shown in Table 1, the control group did not differ from $\mathrm{COPD}_{1}$ patients in terms of median age, the percent of patients under 60 years, $\mathrm{BMI}$ and intensity of smoking. $\mathrm{COPD}_{1}$ patients had only slightly decreased ventilation parameters compared with the controls. A progressive

Table 1. Baseline characteristics of the control group and COPD patients groups according to different degrees of airflow limitation severity (GOLD spirometry level, 2011) on admission (Me; 25, 75)

\begin{tabular}{|c|c|c|c|c|}
\hline Parameters & $\begin{array}{l}\text { Control } \\
n=19\end{array}$ & $\begin{array}{l}\mathrm{COPD}_{1} \\
\mathrm{n}=19\end{array}$ & $\begin{array}{l}\mathrm{COPD}_{2} \\
\mathrm{n}=43\end{array}$ & $\begin{array}{l}\mathrm{COPD}_{3} \\
\mathrm{n}=20\end{array}$ \\
\hline $\begin{array}{l}\text { Median age (years): } \\
<60 />60 \text { years }(\%)\end{array}$ & $\begin{array}{c}52(47 ; 55) \\
70 / 30\end{array}$ & $\begin{array}{c}55(51 ; 58) \\
79 / 21\end{array}$ & $\begin{array}{c}57(53 ; 60)^{*} \\
66 / 34\end{array}$ & $\begin{array}{c}62(56 ; 67)^{* * * * * * *} \\
50 / 50\end{array}$ \\
\hline Body mass index $\left[\mathrm{kg} / \mathrm{m}^{2}\right]$ & $\begin{array}{c}28.6 \\
(27.5 ; 29.2)\end{array}$ & $\begin{array}{c}29.0 \\
(27 ; 32.5)\end{array}$ & $\begin{array}{c}30,3^{*} \\
(26.4 ; 32.2)\end{array}$ & $\begin{array}{c}22.9 * * * * * * * \\
(20.7 ; 27.7)\end{array}$ \\
\hline Present smokers (\%) & 62 & 68 & 77 & $96^{* * * *}$ \\
\hline $\begin{array}{l}\text { Smoking history, index } \\
\text { packs/years }\end{array}$ & $\begin{array}{c}18 \\
(10 ; 30)\end{array}$ & $\begin{array}{c}20 \\
(12 ; 30)\end{array}$ & $\begin{array}{c}21 \\
(12 ; 30)\end{array}$ & $\begin{array}{l}30^{* * * * *} \\
(25 ; 40)\end{array}$ \\
\hline $\begin{array}{l}\text { Median duration of COPD } \\
\text { (years) }\end{array}$ & - & $\begin{array}{c}3 \\
(1 ; 6)\end{array}$ & $\begin{array}{c}9 \\
(4 ; 12)\end{array}$ & $\begin{array}{c}13^{* * * * *} \\
(10 ; 19)\end{array}$ \\
\hline FVC (\% pred.) & $100(98 ; 112)$ & $86(75 ; 90)^{*}$ & $57(48 ; 66)^{*, * *}$ & $39(32 ; 46)^{* * * * * * *}$ \\
\hline $\mathrm{FEV}_{1}(\%$ pred $)$ & $86(77 ; 92)$ & $82(78 ; 87)^{*}$ & $56(50 ; 65)^{* * * *}$ & $33(22 ; 44)^{* * * * * * *}$ \\
\hline $\mathrm{FEV}_{1} / \mathrm{FVC}(\%)$ & $95(89 ; 104)$ & $70(62 ; 72)^{*}$ & $67(57 ; 75)^{*, * *}$ & $51(39 ; 58)^{* * * * * * *}$ \\
\hline SatO $_{2}(\%)$ & $97(96 ; 97)$ & $97(96 ; 97)$ & $96(95 ; 98)$ & $93(90 ; 95)^{* * * * * * *}$ \\
\hline C-reactive protein $[\mathrm{mg} / \mathrm{dL}]$ & $\begin{array}{c}0.3 \\
(0.1 ; 1.8)\end{array}$ & $\begin{array}{c}0.3 \\
(0.1 ; 1.3)\end{array}$ & $\begin{array}{c}4.3^{* * * *} \\
(1.9 ; 8.3)\end{array}$ & $\begin{array}{c}3.3^{* * *} \\
(1.3 ; 5.3)\end{array}$ \\
\hline $\begin{array}{l}\text { Home treatment: } \\
\text { corticoids inhaled/intermit- } \\
\text { tently oral (\%); }\end{array}$ & - & - & $35 / 2$ & $43 / 15^{* * *}$ \\
\hline $\begin{array}{l}\text { with inhaled long acting } \\
\text { anticholinergic (\%); } \\
\text { with inhaled long acting } \\
\beta_{2} \text {-agonists }\end{array}$ & - & - & $\begin{array}{c}22 \\
1\end{array}$ & $\begin{array}{c}7 \\
17^{* * *}\end{array}$ \\
\hline
\end{tabular}

${ }^{*} \mathrm{p}<0.05$ vs. the control group; ${ }^{* *} \mathrm{p}<0.05$ vs. $\mathrm{COPD}_{1} ;{ }^{* * *} \mathrm{p}<0.05$ vs. $\mathrm{COPD}_{2}$ group; Me - median, $25-75 \%$ - interquartile range 
Table 2. Distribution of COPD patients with different severity according to the degree of BMI and LMI (\%)

\begin{tabular}{|c|c|c|c|c|c|c|}
\hline \multirow[t]{3}{*}{ BMI $\left(\mathbf{k g} / \mathbf{m}^{2}\right)$} & \multicolumn{2}{|c|}{ COPD1 } & \multicolumn{2}{|c|}{ COPD2 } & \multicolumn{2}{|c|}{ COPD3 } \\
\hline & \multicolumn{6}{|c|}{ LMI $\left(\mathbf{k g} / \mathbf{m}^{2}\right)$} \\
\hline & $<16.6$ & $>16.6$ & $<16.6$ & $>16.6$ & $<16.6$ & $>16.6$ \\
\hline $\begin{array}{c}\text { Deficiency } \\
\text { BMI }<18.5\end{array}$ & 0 & 0 & 0 & 0 & 5 & 0 \\
\hline $\begin{array}{c}\text { Normal } \\
\mathrm{BMI} \geq 18.5-24.9\end{array}$ & 0 & 10 & 2 & 17 & $30^{* * *}$ & 26 \\
\hline $\begin{array}{c}\text { Overweight } \\
\text { BMI 25.0-29.9 }\end{array}$ & 0 & 50 & 3 & $22^{* *}$ & 0 & $17^{* *}$ \\
\hline $\begin{array}{c}\text { Obesity } \\
\text { BMI }>30.0\end{array}$ & 0 & 40 & 0 & 56 & 0 & $22^{* *}, *^{* *}$ \\
\hline
\end{tabular}

The designations are the same as in the Table 1

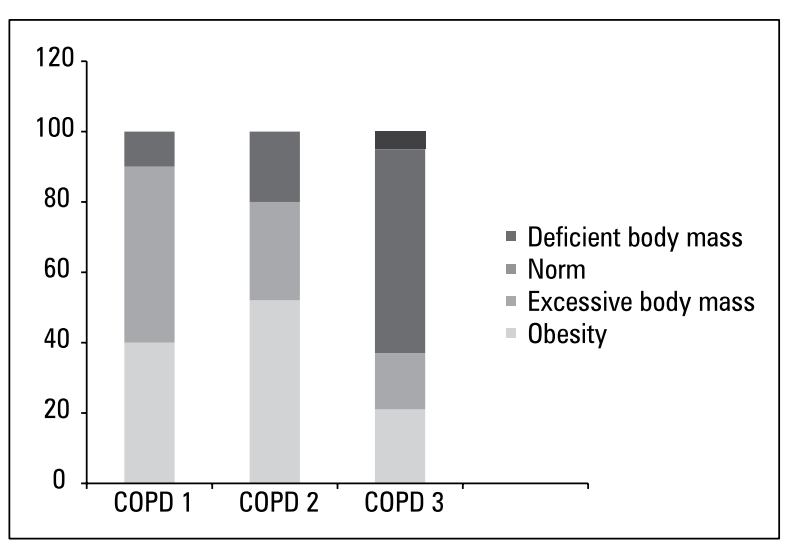

Figure 1. Distribution of COPD patients according to their BMI

decrease in ventilation parameters was noted as the disease became worse: FVC dropped from $86 \%$ in $\mathrm{COPD}_{1}$ to $39 \%$ in $\mathrm{COPD}_{3} ; \mathrm{FEV}_{1}$ and blood oxygen saturation dropped from $82 \%$ to $33 \%$ and from $97 \%$ to $93 \%$ in $\mathrm{COPD}_{1}$ and $\mathrm{COPD}_{3}$ respectively. A significant increase in the number of exacerbations for the past year was found in $\mathrm{COPD}_{3}$ compared with $\mathrm{COPD}_{1,2}$. $\mathrm{COPD}_{3}$ patients had a significantly higher median age, disease duration, MRC breathlessness index and the number of current smokers than the control group and $\mathrm{COPD}_{1,2}$ patients, whereas mean BMI of $\mathrm{COPD}_{3}$ group was significantly lower than in the latter.

As seen from Figure 1, the part of BMI within the normal range was increased (from $10 \%$ in $\mathrm{COPD}_{1}$ to $58 \%$ in $\mathrm{COPD}_{3}$ ) in the course of COPD development, while overweight and obesity were naturally decreased as COPD became worse. Thus, overweight was detected in $50 \%, 28 \%$ and $16 \%$ of $\mathrm{COPD}_{1,2,3}$ patients respectively.
We revealed that the number of patients with decreased LMI level was higher among the patients with normal BMI as the disease progressed (Table 2). We did not detect these patients in $\mathrm{COPD}_{1}$ group, whereas 1 and 6 such patients were revealed in $\mathrm{COPD}_{2,3}$ groups respectively.

Meanwhile decreasing LMI was detected in $5 \%$ of $\mathrm{COPD}_{3}$ patients with low $\mathrm{BMI}$ and in $30 \%$ of these patients against the background of normal values of BMI. The latter was decreased only in severe COPD, but it was in the normal range (or increased to some extent) in most of the observed patients. LMI, BMCI and SMI did not differ in $\mathrm{COPD}_{1}$ from the control (Table 3), whereas in $\mathrm{COPD}_{3}$ these parameters (including FMI) were significantly decreased compared with the control and $\mathrm{COPD}_{1,2}$.

More changes of FM were detected in the trunk and android regions and fewer - in legs and arms. The changes of FM distribution in different body regions had the phased character. There was no difference of FM distribution between $\mathrm{COPD}_{1}$ group and the control. But we revealed significant increase of FM share in arms, legs, trunk, android and gynoid regions in $\mathrm{COPD}_{2}$ group (by 30\%, 31\%, 24\%, 18\% and 19\% respectively vs. the control). Then, in $\mathrm{COPD}_{3}$ group these parameters were decreased to the control values.

Deposition of FM in definite body regions (particularly in trunk and android zone) in COPD patients may be associated with the certain co-morbidities, such as arterial hypertension $(\mathrm{AH})$. Therefore we additionally assessed the influence of $\mathrm{BC}$ distribution upon the presence of AH. Thus, we detected an increased number of COPD patients with concomitant AH: 41\%, 81\% and $74 \%$ in $\mathrm{COPD}_{1,2,3}$ groups respectively. 
Table 3. Distribution of FMI, LMI, BMCI and SMI levels (kg/ ${ }^{2}$ ) among males according to COPD severity (Me; $\left.25 \%, 75 \%\right)$

\begin{tabular}{|c|c|c|c|c|}
\hline Parameter & $\begin{array}{l}\text { Control } \\
n=19\end{array}$ & $\begin{array}{l}\mathrm{COPD}_{1} \\
\mathrm{n}=19\end{array}$ & $\begin{array}{l}\mathrm{COPD}_{2} \\
\mathrm{n}=43\end{array}$ & $\begin{array}{l}\mathrm{COPD}_{3} \\
\mathrm{n}=20\end{array}$ \\
\hline $\mathrm{FMI}$ & $\begin{array}{c}7.2 \\
(6.2 ; 7.7)\end{array}$ & $\begin{array}{c}8.3^{*} \\
(6.2 ; 10.1)\end{array}$ & $\begin{array}{c}9.7^{*} \\
(6.8 ; 11.0)\end{array}$ & $\begin{array}{c}4.7^{* * * *, * * *} \\
(3.1 ; 9.3)\end{array}$ \\
\hline LMI & $\begin{array}{c}20.3 \\
(19.9 ; 22.0)\end{array}$ & $\begin{array}{c}20.8 \\
(20.1 ; 21.4)\end{array}$ & $\begin{array}{c}20.1^{* *} \\
(18.8 ; 21.2)\end{array}$ & $\begin{array}{c}17.7^{* * * * * * * *} \\
(16.5 ; 18.9)\end{array}$ \\
\hline $\mathrm{BMCl}$ & $\begin{array}{c}1.06 \\
(0.99 ; 1.12)\end{array}$ & $\begin{array}{c}1.04 \\
(0.97 ; 1.08)\end{array}$ & $\begin{array}{c}1.01 \\
(0.92 ; 1.08)\end{array}$ & $\begin{array}{c}0.89 * * * * * * \\
(0.83 ; 0.94)\end{array}$ \\
\hline SMI & $\begin{array}{c}9.34 \\
(8.76 ; 9.70)\end{array}$ & $\begin{array}{c}9.41 \\
(8.81 ; 9.74)\end{array}$ & $\begin{array}{c}8.92^{* * * *} \\
(8.05 ; 9.51)\end{array}$ & $\begin{array}{c}7.61^{*}, * * * * * \\
(7.13 ; 8.38)\end{array}$ \\
\hline
\end{tabular}

The designations are the same as in the previous Table 1

$\mathrm{FMI}$ — fat mass index, $\mathrm{LMI}$ - lean mass index, $\mathrm{BMCl}$ - bone mineral component index, $\mathrm{SMI}$ - skeletal muscle index

There were significant differences between $\mathrm{COPD}_{1}$ and $\mathrm{COPD}_{2,3}$ groups according to the share of patients with concomitant $\mathrm{AH}\left(\chi^{2}=12.52\right.$ and $\chi^{2}=3.68$ respectively). COPD isolated group did not differ from COPD plus AH group according to age, disease severity and smoking status, while BMI was higher in the latter (30 vs. 25.3 $\left.\mathrm{kg} / \mathrm{m}^{2} ; \mathrm{p}<0.05\right)$. A similar picture was observed concerning the levels of triglycerides (1.59 and $1.16 \mu \mathrm{mol} / \mathrm{L}$ respectively; $\mathrm{p}<0.05)$ and glucose (5.7 and $5.2 \mu \mathrm{mol} / \mathrm{L}$ respectively; $\mathrm{p}<0.05$ ). We revealed (Table 4) significant difference of all BC parameters in COPD patients with concomitant AH compared with pure COPD patients. The central type of FM deposition (with excess FM accumulation in android region) prevailed in COPD male patients with concomitant $\mathrm{AH}$.

The leptin and TNF- $\alpha$ level was increased during COPD progression by 18\%, 75\%, 79\% and by $21 \%, 52 \%$ and $64 \%$ respectively in $\mathrm{COPD}_{1,2}$, ${ }_{3}$ groups compared with the control $(\mathrm{p}<0.05$ for $\mathrm{COPD}_{2,3}$ ). The level of free testosterone was variable, depending on the severity of the disease. It was the highest in mild COPD $\left(\mathrm{COPD}_{1}\right)-7.6$ $\mathrm{pg} / \mathrm{mL}$ and significantly lower in severe COPD $\left(\mathrm{COPD}_{3}\right)-5.2 \mathrm{pg} / \mathrm{mL}$.

\section{Discussion}

BC abnormalities can modulate functional limitation in COPD independent of airflow obstruction degree. We detected median BMI decrease in severe COPD patients against the background of increased patients share with normal BMI during COPD development. Weight loss may involve all tissue compartments, although loss of skeletal muscle may be particularly important in COPD due to wasting of respiratory muscles with following loss of their power and endurance [23].
Table 4. Distribution of body FM in different body regions and their relations in COPD patients with/without concomitant $\mathrm{AH}$ (Me; 25\%,75\%)

\begin{tabular}{lcc}
\hline Region & $\begin{array}{c}\text { COPD isolated } \\
\mathbf{n}=\mathbf{2 6}\end{array}$ & $\begin{array}{c}\text { COPD with AH } \\
\mathbf{n}=\mathbf{5 9}\end{array}$ \\
\hline Arms (\%) & 18.7 & $24.9^{*}$ \\
& $(13.9 ; 24.6)$ & $(20.0 ; 29.0)$ \\
Legs (\%) & 21.5 & $26.1^{*}$ \\
& $(16.6 ; 25.9)$ & $(22.5 ; 31.0)$ \\
Trunk (\%) & 28.8 & $36.2^{*}$ \\
& $(16.9 ; 35.0)$ & $(32.1 ; 39.2)$ \\
Android (\%) & 31.4 & $41.4^{*}$ \\
& $(22.3 ; 40.6)$ & $(36.2 ; 45.2)$ \\
Gynoid (\%) & 26.8 & 30.2 \\
Total level of FM (\%) & $(21.1 ; 31.9)$ & $(26.8 ; 34.4)$ \\
Total level of LM (\%) & 25.8 & $31.1^{*}$ \\
Android/gynoid & $(17.3 ; 30.7)$ & $(26.9 ; 34.5)$ \\
regions & 74.2 & $69.3^{*}$ \\
Trunk/total FM & $(69.3 ; 82.7)$ & $(65.5 ; 72.5)$ \\
& 1.12 & $1.28^{*}$ \\
Legs/total FM & $(1.04 ; 1.27)$ & $(1.18 ; 1.42)$ \\
Arms +legs/trunk & 0.56 & $0.61^{*}$ \\
& $(0.54 ; 0.60)$ & $(0.58 ; 0.65)$ \\
The designations are the same as in the previous Table 1 & \\
* $\mathrm{p}<0,05$ between these groups; & & $0.26^{*}$ \\
& 0.30 & $(0.24 ; 0.29)$ \\
& $(0.26 ; 0.33)$ & $0.59^{*}$ \\
& 0.71 & \\
& $(0.60 ; 0.80)$ & $(0.51)$ \\
\hline
\end{tabular}

BMI did not give the complete information about $\mathrm{BC}$ changes in our patients because BMI remained within the normal range (or slightly increased) in most of them. Probably, overweight can reduce the cost of breathing in COPD with better mechanical efficiency of respiratory muscle. Also advanced COPD may accelerate the impact of BC structural changes that occur with normal ageing [24]. 
The level of FMI was increased in $\mathrm{COPD}_{1,2}$ (could mask the loss of muscular and bone tissues) and then decreased in $\mathrm{COPD}_{3}$ group. This depletion of FMI, LMI, BMCI and SMI in severe COPD was largely related to the increased level of tissue hypoxia, pulmonary systemic inflammation (through inflammatory cytokines), intensive smoking and catabolic metabolism. Thus, the "frequent exacerbators" (mostly patients with severe COPD) had lower levels of these BC parameters. This relationship was strengthen by the finding of increased circulating levels of CRP and TNF- $\alpha$ in severe COPD patients who might have a longer exposure to inflammation before entering the study. Probably, faster decline in FM, LM, BMCI and SMI in severe COPD patients with low BMI were significantly related to older age and lower $\mathrm{FEV}_{1}$. We can suppose that decrease of BMI, FMI, LMI and SMI in severe COPD patients is an adaptation to deficient intake of energy and substrates as well as it has reduces airflow limitation by improving peripheral airway function, because a smaller airways are constrained to a greater extent by visceral fat than larger airways. Our results suggest that disorders of BC distribution occur before being underweight. Thus, asymptomatic loss of skeletal muscle may occur in up to $25 \%$ of COPD patients with normal BMI [25].

Depletion of muscle mass (which may be roughtly estimated by LMI level) can significantly affect peak oxygen consumption and ventilatory response in severe COPD patients. LM or SMI (as surrogate markers) are still more suitable in detecting muscular wasting than BMI due to an unapparent and asymptomatic loss of skeletal mass [26]. Probably, in COPD the impairment first develops in the respiratory muscles strength (that is affected more, than peripheral muscle force) preceding the obvious changes of pulmonary function.

We cannot detect characteristic changes of LMI, SMI and BMCI in mild-to-moderate COPD. Probably, DXA method assessed not entirely LM or SMI but included smaller and highly metabolically active ectopic FM within and around the skeletal muscle and viscera. Therefore, our findings in respect to BC distribution in overweight COPD men could be to a certain extent explained by the excess of ectopic FM. The loss of muscle mass was aggravated by infiltration of muscles by fat that leads to decreased muscle strength and their inadequate functioning. It was shown, that intramuscular fat infiltration was more pronounced in moderate-to severe COPD male patients [27]. There was a positive correlation between LMI and SMI $(\rho=0.87, \mathrm{p}<$ 0.05 ) in entire COPD group, showing that they are interrelated and reflected the decrease in skeletal muscles component.

The short courses treatment with sCS was used only in one moderate COPD patient and in three severe COPD patients. Therefore, we do not think that our findings can be partially explained by the effect of sCS on the repartition of FM and LM.

Segmental BC assessment more often detected central types of obesity (increase of FM ratio in the trunk region to total FM and decreased level of legs FM to total FM) than peripheral type in our COPD patients. A various distributions of FM may have varying mechanical and inflammatory properties as well as consequent COPD-related effects. Thus, trunk FM (collection of fat compartments with varying metabolic activity) may have a greater mechanical impact on diaphragmatic movement, chest wall recoil and FVC than FM of arms or legs [28].

The absence of significant differences between the control and mild COPD according to the distribution of FM in arms, legs and trunk as well as the presence of these differences in moderate COPD could be due to the fact that skeletal muscle in different body regions may have different metabolic and inflammatory effects in advanced stage of disease. Probably, the location of smaller ectopic fat deposits become more important in advanced COPD (due to higher inflammatory status) than larger size of fat deposits [29].

We detected a direct effect of disturbed BC on lung function. There were a significant correlations between LMI, BMCI and $\mathrm{FEV}_{1}$, FVC $(\rho$ $=0.34,0.39$ and $\rho=0.34,0.32$ respectively) as well as dyspnea severity $(\rho=-0.44$ and -0.38 respectively). These correlations indicate that decreased muscular and bone tissue components of COPD patient's BC were combined with the disorders of lung function and lowered tolerance to physical activity. BMCI had a significant correlation with $\mathrm{SpO}_{2}$ and MRC score $(\rho=0.46$ and $\rho=-0.36$ respectively). These data emphasize a negative influence of severe hypoxia on muscular and bone tissue components of BC in COPD patients. Our study revealed increased concentrations of leptin and TNF- $\alpha$ against the background of free testosterone level decrease during COPD development. Similar changes of leptin and TNF- $\alpha$ levels in general COPD group were noted $(\rho=0.32, \mathrm{p}<0.05, \mathrm{n}=82)$. They may be due to the production of these factors by fat tissue. Additionally, we detected a significant correlation 
between free testosterone, leptin level and FMI $(\rho=-0.38,0.33$ respectively), indicating that low free testosterone level was associated with increased body FM in mild-to-moderate COPD male patients $[17,30]$. The presence of positive correlation between FMI and leptin level could be explained by the association of intramuscular fat with high leptin concentrations and increased expression of TNF- $\alpha$.

\section{Conclusions}

BMI was within the normal range (or was even increased) in many of mild-to moderate COPD male patients and did not give a complete information about BC changes. The levels of FMI, LMI, BMCI and SMI were decreased only in severe COPD group, while FMI was increased in mild-to-moderate COPD. Severe COPD was associated with decreased share of FM in the arms, legs, trunk as well as in android and gynoid regions.

Our findings suggest a likely multifactorial basis for BC abnormalities in male COPD patients. Initially (mild-to-moderate COPD) BMI and BC parameters were within the normal range. Later, as COPD progresses, significant changes in $\mathrm{BC}$ were noted. These findings showed that the assessment of BC may be useful clinically for evaluation of COPD patients.

\section{Conflict of interest}

The authors declare no conflict of interest.

\section{References:}

1. Celli B, Cote C, Marin J. The body mass index, airflow obstruction, dyspnea and exercise capacity index in COPD. N Engl J Med 2004; 350: 1005-1012.

2. Kiyokawa H, Muro S, Oguma N. Impact of COPD exacerbation on osteoporosis. COPD. 2012; 9: 235-242. doi: 10.3109/15412555.2011.650243.

3. Prescott E, Almdal T, Mikkelsen KL, Tofteng CL, Vestbo J, Lange P. Prognostic value of weight change in COPD: results from the Copenhagen City Heart Study. Eur Respir J 2002; 20: 539-544.

4. Debigare R, Cote C, Maltais F. Peripheral muscle wasting in chronic obstructive pulmonary disease: clinical relevance and mechanisms. Amer J Respir Crit Care Med 2001; 164 1712-1717.

5. Nevzorova V, Barchatova D. Systemic inflammation and skeletal muscles status in COPD patients. Therap Archive Russia 2008; 80: 85-90.

6. Solntseva A. Endocrinal effects of fat tissue. Med News (Belarus) 2009; 3: 7-11.
7. Ukraintsev S, Brezhneva T. Cachexia in COPD: diagnosis and treatment. Pulmonology (Russia) 2012; 3: 104-107.

8. Vasilkova T. Clinical peculiarities and pathogenic mechanisms of COPD development against the background of obesity. Med Sci Edu Ural (Russia) 2008; 4: 8-10.

9. Cano N, Pichard C, Roth H. C reactive protein and BMI predict outcome in end stage respiratory failure. Chest 2004; 126: 540-546.

10. Vesto J, Prescott E, Almdal T. Body mass, fat free body mass and prognosis in patients with COPD from a random population sample. Am J Respir Crit Care Med 2006; 173: 79-83.

11. Schols A, Soeters B, Dingemans A. Prevalence and characteristics of nutritional depletion in patients with stable COPD eligible for pulmonary rehabilitation. Am Rev Respir Dis 1993; 147: 1151-1156.

12. Wouters E. Nutrition and metabolism in chronic respiratory disease. Eur Respir Monograph 2003; 8: 180.

13. Waschki B. Physical activity is the strongest predictor of allcause mortality in patients with COPD. Chest 2011; 140: 331359. doi: 10.1378/chest.10-2521.

14. Kupeli E, Ulubay G, Ulasi S. Metabolic syndrome is associated with increased risk of acute exacerbation of COPD. Endocrine 2010; 38: 76-82. doi: 10.1007/s12020-010-9351-3.

15. Rutten E, Calverley PM, Casaburi R et al. Changes in body composition in patients with COPD. Do they influence patient-related outcomes? Ann Nutr Metab 2013; 63: 239-247. doi: 10.1159/000353211.

16. Jordan JG, Mann JR. Obesity and mortality in persons with COPD using data from the NHANES III. South Med J 2010; 103: $232-$ 235. doi: 10.1097/SMJ.0b013e3181d394b4.

17. Blouin K, Richard C, Brochu G et al. Androgen inactivation and steroid-converting enzyme expression in abdominal adipose tissue in men. Endocrinol 2006; 191: 637-649.

18. Krommidas G, Kostikas K, Papatheodorou G et al. Plasma leptin and adponectin in COPD exacerbations: associations with inflammatory biomarkers. Respir Med 2010; 104: 40-46. doi: 10.1016/j.rmed.2009.08.012.

19. Karsenty G. Convergence between bone and energy homeostasis: Leptin regulation of fat and bone mass. Cell Metabolism 2006; 4: 341-348.

20. Poulain M, Doucet M, Drapeau V et al. Metabolic and inflammatory profile in obese patients with COPD. Chron Respir Dis 2008; 5: 35-41. doi: 10.1177/1479972307087205.

21. Dharmagunawardena R, Zammit C, Makker H. Prevalence and predictors of obesity hypoventilation syndrome. Int J Respir Care 2011; 7: 10-13.

22. Ali Assad N, Sood A. Leptin, adiponektin and pulmonary diseases. Biochimie 2012; 94: 2180-2189. doi: 10.1016/j.biochi.2012.03.006

23. Nishimura Y, Tsursumi M, Nakata H et al. Realtionship between respiratory muscle strength and lean body mass in men with COPD. Chest 1995; 107: 1232-1236.

24. Eisner M, Blanc P, Sidney S et al. Body composition and functional limitation in COPD. Respir Res 2007; 8: 7-12.

25. Shoup R, Dalsky G, Warner S et al. Body composition and health-related quality of life in patients with COPD. Eur Respir J 1997; 10: 1576-1578.

26. Gosselink R, Troosters T, Decramer M. Distribution of muscle weakness in patients with stable COPD. J Cardiopulm Rehabil 2000; 20: 353-360.

27. Makarevich A, Lemiashevskaya S, Postavcev A et al. The dynamics of respiratory muscle changes during the progression of COPD. Adv Clin Exp Med (Poland) 2014; 23: 381-394.

28. O'Donnell D, Deesomchok A, Lam YM et al. Effects of BMI on static lung volumes in patients with airway obstruction. Chest 2001; 140: 461-468.

29. Mailo C, Mohamed E, Carbonelli M. Body composition and respiratory function. Acta Diabetol 2003; 40: 32-38.

30. Blouin K, Tchernof A. Androgens and body fat distribution. J Steroid Biochem Mol Biol 2008; 108: 272-280. 